\title{
Some properties of composite corn cob and sawdust particle boards
}

\author{
A. Banjo Akinyemi ${ }^{\text {a,* }}$, J.O. Afolayan ${ }^{\text {b }}$, E. Ogunji Oluwatobi ${ }^{c}$ \\ ${ }^{a}$ Department of Agricultural and Biosystems Engineering, Landmark University, P.M.B.1001 Omuaran, Kwara State, Nigeria \\ ${ }^{\mathrm{b}}$ Department of Civil and Environmental Engineering, Federal University of Technology Akure, Nigeria \\ ${ }^{\mathrm{c}}$ Department of Civil Engineering, Landmark University Omuaran, Nigeria
}

\section{H I G H L I G H T S}

- Particle boards from corncob and sawdust with urea formaldehyde as binder showed good prospect.

- Selected physical and mechanical properties were determined.

- Indoor application is recommended.

\section{A R T I C L E I N F O}

\section{Article history:}

Received 7 September 2015

Received in revised form 22 September

2016

Accepted 6 October 2016

\section{Keywords:}

Corncob

Sawdust

Particle board

Properties

MOR

MOE

\begin{abstract}
A B S T R A C T
This research examined the possibility of developing a composite corncob (CC) and sawdust (SD) particle board using urea formaldehyde as binder. The panels were produced using $0 \%, 25 \%, 50 \%, 75 \%$ and $100 \%$ variations for both agricultural wastes with a constant volume of adhesive to evaluate their effect on the physical and mechanical properties. The results showed that $25 \%$ and $50 \%$ replacement of SD with CC had favourable physical properties recommendable for indoor uses in buildings. In contrast, the particleboards cannot be recommended for load bearing purposes based on poor mechanical properties which improved as the composition of CC increased from $25 \%$ to $75 \%$ and also because it failed to satisfy European Standard requirements. 75\% CC replacement had the highest value for both MOR and MOE but possessed poor physical properties. Within the experimental investigation and possible limitations the panels with 50\% CC replacement were the most preferred since they had preferable performances for both physical and mechanical properties.
\end{abstract}

(c) 2016 Elsevier Ltd. All rights reserved.

\section{Introduction}

A lot of housing challenges are faced by most developing countries which have created a lot of housing shortages as a result of high interest rates, increased taxes, high labour costs and government policy bottlenecks. Most banks are not interested in financing housing construction through provision of loans and where it is available the interest and collateral requested are ridiculous, as a result of these challenges, a larger percentage of the populace live in sub-standard and ramshackle buildings. As a way of finding a lasting solution to these problems, lots of researches are being conducted on the use of non-conventional building materials which has the same properties as those popularly used for development of structures [1]. Most of the developing countries are very rich in agricultural and natural fibre since majority are peasant farmers who produce rice, palm trees, sugarcane and a lot of other crops

\footnotetext{
* Corresponding author.

E-mail address: bantonbows@gmail.com (A.B. Akinyemi).
}

accompanied with a large portion of agricultural wastes which are used as fuel or burnt off in disposal sites thereby constituting health hazards. It has been observed through various researches that these natural fibres have very good physical and mechanical properties and have the potential of being used in the development of different materials for various building applications [2-4]. Particleboard (PB) is a panel product made of wood products or other materials having lignocellulose properties bonded together by urea formaldehyde or other synthetic resin under high temperature and pressure to produce sheets [5-8]. Particleboards are light weight boards that can be used as thermal insulators, ceiling boards, wall partitions, doors and some other household furnitures [9]. Agrowastes are being incorporated into green buildings because they are usually more economical at the long run. This led to the development of new environmentally friendly technologies for turning agricultural residues like maize cob, rice husk, groundnut shell $[10,11]$ coconut coirs, durian peel [12,13] bamboo [14], bagasse, wheat straw, chir pine needles, chilli pepper stalks [15] woven cotton fabrics, rubber wood [16] cotton stalks, red cedar [17] and 
banana stem among others into quality value-added composite particle board products using conventional formaldehyde-based resins [2]. Some works have been done on development of composite particle and ceiling boards from both industrial and agricultural products in Nigeria. Sawdust, waste paper and starch were varied by weight to produce a ceiling board with good physical, mechanical and thermal conductivity properties [18]. Olorunmaiye and Ohijeagbon [19] also developed a composite particle board from wood waste and jatropha curcas seed cake with an observed improvement in the mechanical properties. In another study, general purpose particle boards which satisfied ANSI/A208.1-1999 specification were produced from cassava stalks and corn cobs [20]. Cengiz et al. [21] developed a composite particleboard panel by varying the sunflower stalks and calabrian pine percentage compositions using $100,75,50,25$ and $0 \%$ roportions. In a similar research, particles of empty fruit bunch of Elaeis guineensis, pineapple leaves, and Tetra Pak packages were mixed with 3 kinds of wood from Gmelina arborea, Tectona grandis and Cupressus lusitanica in 50:50, 70:30, and 90:10 variations [22]. The objectives of this research were to determine some physical and mechanical properties of composite corn cob and sawdust particles in a predetermined proportions.

\section{Materials}

The materials used for the production of composite particleboard from corn cob and saw dust were sourced locally from the Landmark University community. These include $30 \mathrm{~kg}$ of corn cob (CC), $30 \mathrm{~kg}$ of saw dust (SD) which was from saw milled Mahogany specie of timber, Urea Formaldehyde resin (Top Bond) and plywood for the construction of moulds.

\section{Methodology}

\subsection{Preparation of Corn $\mathrm{Cob}$}

The CC was collected at an average moisture content of $6.44 \%$, room dried for 7 days to an average of $6.18 \%$ moisture content and manually crushed using a wooden mortar and pestle (Plate 1 ). The CC was hammer milled and sieved (Plate 2) so as to obtain particles passing through a B.S. sieve of aperture $3 \mathrm{~mm}$ and retained in a sieve of aperture $1.18 \mathrm{~mm}$. The particles retained were re-milled and re-sieved while the particles that pass through the $1.18 \mathrm{~mm}$ sieve were discarded.

The volume of CC particles required for the production of 20 panels for the experimental design shown in Table 1 was $70,000 \mathrm{~cm}^{3}$. The processed CC particles were weighed and the weight recorded as initial weight. Thereafter, these particles were

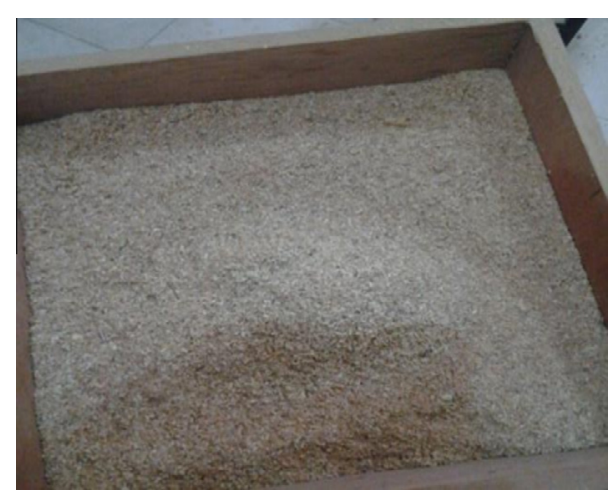

Plate 2. Milled and sieved.

Table 1

Experimental mix.

\begin{tabular}{llll}
\hline $\begin{array}{l}\text { Composition } \\
\text { code }\end{array}$ & $\begin{array}{l}\text { Composition of SD } \\
(\%)\end{array}$ & $\begin{array}{l}\text { Composition of CC } \\
(\%)\end{array}$ & Replicates \\
\hline C1 & 100 & 0 & 4 \\
C2 & 75 & 25 & 4 \\
C3 & 50 & 50 & 4 \\
C4 & 25 & 75 & 4 \\
C5 & 0 & 100 & 4 \\
\hline
\end{tabular}

conditioned in the oven at $60{ }^{\circ} \mathrm{C}$ for $24 \mathrm{~h}$ to achieve a new equilibrium moisture content of $3 \%$ of the initial.

\subsection{Preparation of saw dust}

The SD was sourced from the dumpsite within the University at a moisture content of $12.54 \%$ when analyzed with the aid of AND MX-50 moisture analyzer, room dried for 7 days, oven dried at $60{ }^{\circ} \mathrm{C}$ for $24 \mathrm{~h}$ till the moisture content reduced to $9.41 \%$ and sieved (Plate 3) using B.S. sieves of $3 \mathrm{~mm}$ and $1.18 \mathrm{~mm}$ apertures to remove oversized and undersized particles, enhance uniformity and improve homogeneous mixing. The volume of CC particles required for the production 20 panels for the experimental mix in Table 1 was $70,000 \mathrm{~cm}^{3}$.

\subsection{Production of composite particle board}

To produce the composite, the calculated volumes of particles required as shown in Table 2 were measured using a graduated bucket. The different compositions were then batched into black

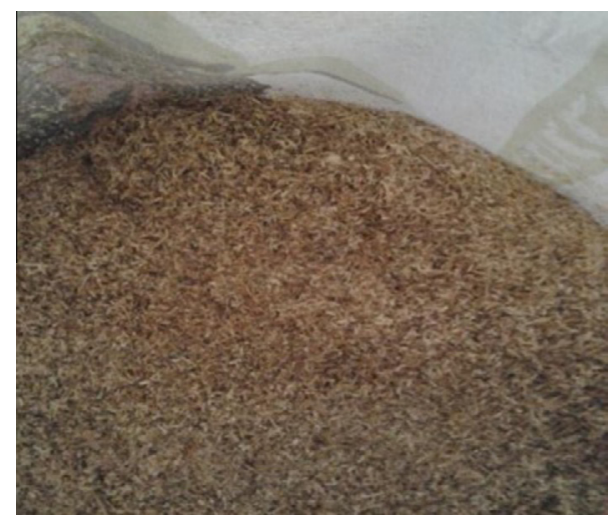

Plate 3. Sieved saw dust CC particles. 
Table 2

Batching of composite.

\begin{tabular}{llll}
\hline $\begin{array}{l}\text { Composition } \\
\text { code }\end{array}$ & $\begin{array}{l}\text { Composition for batching SD:CC } \\
(\%)\end{array}$ & V.E. $\left(\mathrm{cm}^{3}\right)$ & $\begin{array}{l}\text { V.A. } \\
\left(\mathrm{cm}^{3}\right)\end{array}$ \\
\hline C1 & $100: 0$ & $7000: 0$ & 2100 \\
C2 & $75: 25$ & $5250: 1750$ & 2100 \\
C3 & $50: 50$ & $3500: 3500$ & 2100 \\
C4 & $25: 75$ & $1750: 5250$ & 2100 \\
C5 & $0: 100$ & $0: 7000$ & 2100 \\
\hline
\end{tabular}

Note: V.E means volume equivalent and V.A. means volume of adhesive used which is $30 \%$ of batch volume.

cellophane bags and tightly sealed. These bags were labelled according to their SD:CC compositions.

The measured adhesive volume was poured into the head pan and half of the particles batched in the cellophane were first poured into the head pan and thorough mixing was done with hand after which the remaining particles were emptied into it and mixed until the adhesive was uniformly distributed and a homogeneous mixture obtained (Plate 4). This process was repeated for the batched compositions, $\mathrm{C} 1, \mathrm{C} 2, \mathrm{C} 3, \mathrm{C} 4$ and $\mathrm{C} 5$ to produce the replicates.

\subsection{Casting and pressing operations}

The homogeneous mixture obtained was transferred into the moulds filling it to a thickness of $35 \mathrm{~mm}$ which is 1.5 times the intended $20 \mathrm{~mm}$ panel thickness. A rectangular wooden rod was then used to tamp (Plate 5) the composite in order to remove air voids and also to give a compacted surface. The mould cover was put in place and the mould transported to the hydraulic jack for compression. A metal slab was placed on it before compressing to close the mould to $20 \mathrm{~mm}$ which is the desired thickness of the composite slab at room temperature. The mould cover was tied with a metal strip to ensure that the cover remained tightly fixed before removing from the hydraulic jack. The pressure was maintained for $10 \mathrm{~min}$, after which they were transferred into the oven and allowed to dry for $1 \mathrm{~h}$ at $80^{\circ} \mathrm{C}$. The moulds were then removed from the oven and allowed to cool for $10 \mathrm{~min}$ before the compacting pressure (the cover) was removed and left for $24 \mathrm{~h}$. After $24 \mathrm{~h}$ the panels were removed from the mould, returned into the oven to dry for $3 \mathrm{~h}$ at $130^{\circ} \mathrm{C}$ and allowed to cool slowly in the oven for $30 \mathrm{~min}$ before they were removed and placed on a flat surface to cool for $1 \mathrm{~h}$ before stacking. In all, 20 panels were cast which were cut into smaller pieces for the various tests (Plate 6).

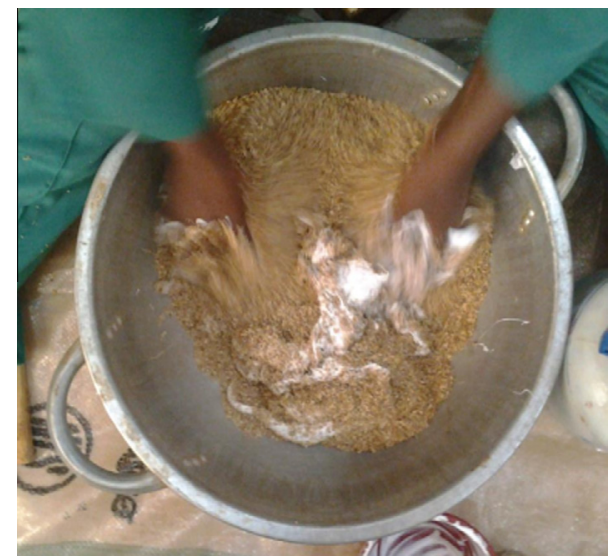

Plate 4. Hand mixing.

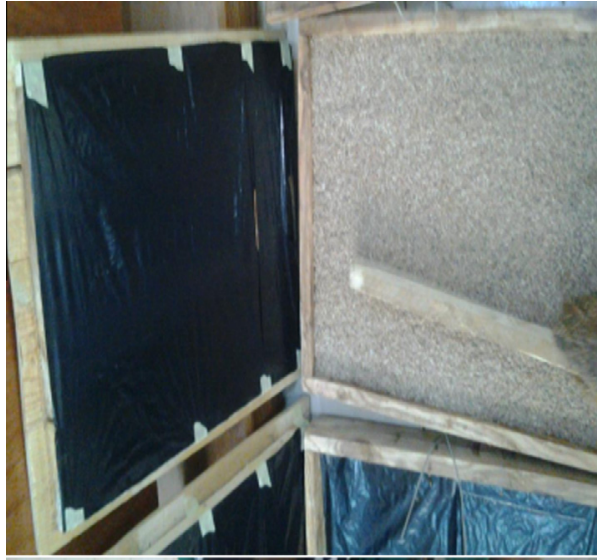

Plate 5. Tamping with rod.

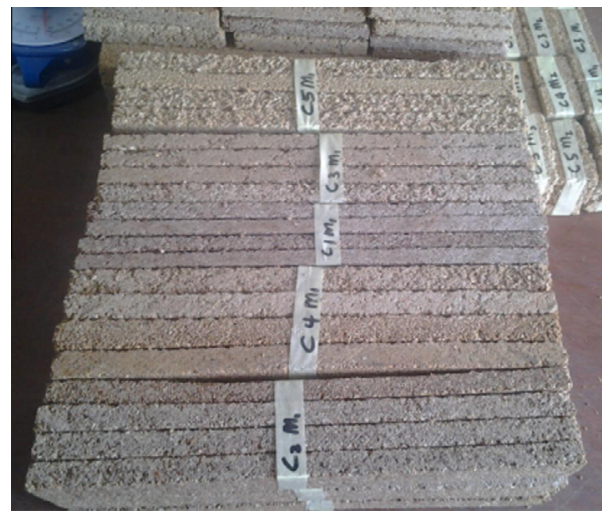

Plate 6. Composite SD and CC particle boards.

\subsection{Physical property determination}

\subsubsection{Density test}

Density is a ratio of the mass of each test piece to its volume, both measured at the same moisture content. The tests were carried out based on the BS EN 323 [23].

\subsubsection{Water absorption test}

The water absorption (WA) test was carried out to determine the amount of water the particleboard can absorb after 2 and $24 \mathrm{~h}$ immersion.

\subsubsection{Thickness swelling test}

This is a dimensional analysis test which was used to determine the change in the thickness of the sample after it has been immersed in water for a given period of time. It was used to determine the effect of water on the thickness of the board by using a digital vernier caliper to measure the changes before and after immersion in water.

\subsection{Mechanical property determination}

\subsubsection{Static bending test}

The universal testing machine was used to carry out the tests following the central concentration loading method (Plate 7). From this test, the modulus of rupture (MOR) and modulus of elasticity (MOE) of the specimen were determined. MOR and MOE are measured in $\mathrm{N} / \mathrm{mm}^{2}$. These tests were carried out in accordance with BS EN 310 [24]. Before the test was conducted the test pieces were 


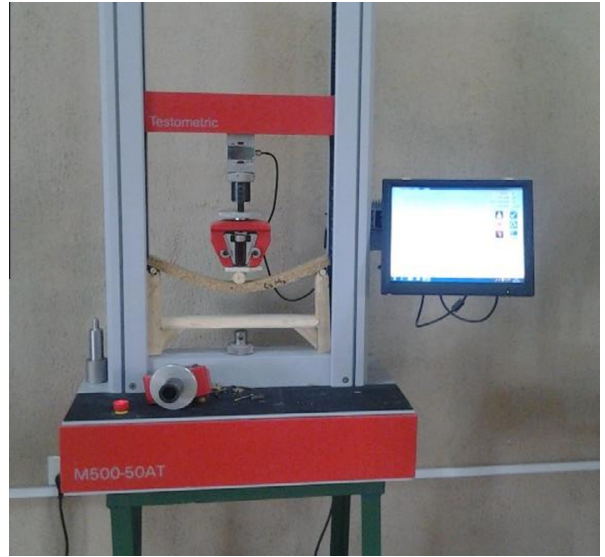

Plate 7. Static bending test using UTM.

conditioned as specified in BS EN 310 until the results of two consecutive weighing operations carried out at an interval of $24 \mathrm{~h}$ did not vary by more than $0.1 \%$ of the test piece mass.

\section{Results and discussion}

\subsection{Physical properties}

\subsubsection{Density test}

The mean density values obtained for $100 \%$ SD and CC panels were $436 \mathrm{~kg} / \mathrm{m}^{3}$ and $413 \mathrm{~kg} / \mathrm{m}^{3}$ respectively. While the mean values for various percentage combination of CC and SD panels ranged from $413 \mathrm{~kg} / \mathrm{m}^{3}$ to $486 \mathrm{~kg} / \mathrm{m}^{3}$ as shown in Fig. 1 which are similar to the values obtained by Rose et al., [25] and Idris et al., [26]. It was observed that the panel densities increased as the SD composition reduces until the peak was achieved at C4 with 25\% SD after which the value dropped drastically, but there was an observed slight increment in the density as the percentage of CC increases but a sharp drop was observed after the peak was reached at C4 with 75\% CC. Therefore, from the data obtained in Fig. 1, CC panels were of lower density compared to the SD panels. The densities obtained are comparable to the particleboard densities of 590 and $800 \mathrm{~kg} / \mathrm{m}^{3}$ of wood product industries. The variation of each mix was also evident from the standard error bars in Fig. 1.

Since the maximum density, $486 \mathrm{~kg} / \mathrm{m}^{3}$ is less than $640 \mathrm{~kg} / \mathrm{m}^{3}$, therefore the manufactured boards can be graded according to ANSI as a low density particleboard, Grade 1 (LD-1) [27].

\subsubsection{Water absorption test}

After $2 \mathrm{~h}$ of immersion in water $\mathrm{C} 2$ was observed to have the least value for WA while C5 which is $100 \%$ CC had the highest value of water absorption. Similarly, after $24 \mathrm{~h}$ of immersion of the spec-

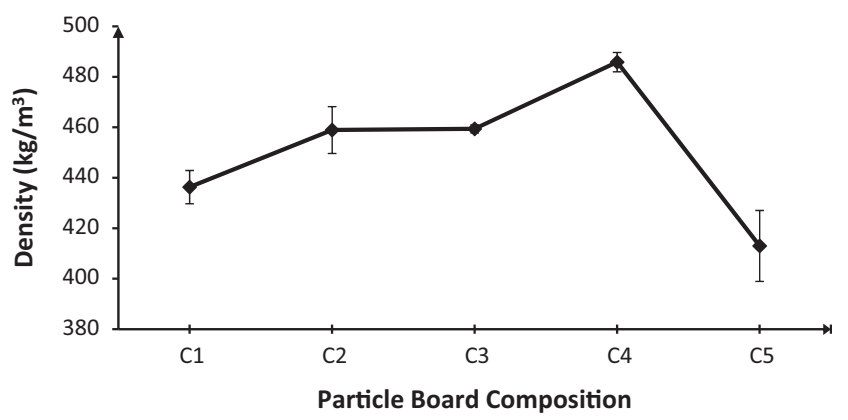

Fig. 1. Density of composite particle board. imen in water C2 still had the least value of WA followed by C3, C4, and $\mathrm{C} 1$ respectively and $\mathrm{C} 5$ had the highest value of WA as shown in Table 3. Therefore, from this test, $\mathrm{C} 2$ which is a combination of $75 \%$ SD and 25\% CC had a better performance when compared with C1 which is $100 \%$ SD. C1, C3 and C4 were seen to have similar performances after $24 \mathrm{~h}$ of immersion in water. A significant decrease in WA was noticed with the initial $25 \%$ replacement of SD with CC, but subsequent increase in CC percentage led to increase in WA as seen in Table 3. The initial decrease in WA can be explained by the increase in the compaction of the panels. SD can be said to possess higher compressibility when compared with CC because when equal pressure is applied to equal volumes of SD and CC contained in different containers, SD was observed to compress more than CC. Therefore when the less compressible CC was added to the more compressible SD less void spaces were present thereby giving less room for the penetration of water.

However, the subsequent increase in WA as a result of increase in CC can be attributed to the fact that the ability of the adhesive to bind the particles reduces as the agricultural residue increases. C5 was observed to flake off easily with the application of little pressure after curing thereby buttressing the fact that the binding ability of the adhesive is least in $\mathrm{C} 5$, this also explains the increase in WA with increase in CC. Scatolino et al. [28] also observed similar increase in WA with increase in CC against pinewood after $24 \mathrm{~h}$..

\subsubsection{Thickness swelling test}

Variation in the thickness of the boards were observed after casting and curing, this variation can be explained by the fact that the moulds used in casting the panels were wooden and did not possess a uniformly flat surface. Furthermore, the variation in thickness as shown in the $0 \mathrm{~h}$ column on the thickness swelling table can be attributed to the non-uniform distribution of the compressive load during the compaction process.

From the data obtained from the tests that were carried out as shown in Fig. 2, C2 swells least after 2 h, but after 24 h of immersion in water C3 exhibits the least swelling compared to the other board types.

The thickness swelling difference between 2 and $24 \mathrm{~h}$ of water immersion was observed to reduce as the percentage of CC increases. This can be easily spotted in Fig. 2 as the 2 and $24 \mathrm{~h}$ line graphs converge as CC increases thereby suggesting that, the higher the CC composition the faster it is for the boards to get saturated with water. For physical properties $\mathrm{C} 3$ had the best performance followed by $\mathrm{C} 2$, while $\mathrm{C} 5$ had the poorest physical property performance.

\subsection{Mechanical properties}

\subsubsection{Static bending}

Modulus of rupture (MOR) was seen to increase with the addition of CC up to $75 \%$ but decreased afterwards. C4 had the highest value for MOR while C5 had the least value as shown in Fig. 3. Modulus of elasticity (MOE) also showed a similar increase and decrease pattern in values as shown in Fig. 4 where $\mathrm{C} 1$ had the least value which was $54.418 \mathrm{~N} / \mathrm{mm}^{2}$ and C4 had the highest value, $82.555 \mathrm{~N} / \mathrm{mm}^{2}$.

Table 3

Mean values for water absorption tests.

\begin{tabular}{lll}
\hline Board type & \% WA after $2 \mathrm{~h}$ & \% WA after $24 \mathrm{~h}$ \\
\hline C1 & 58.77 & 121.06 \\
C2 & 49.85 & 106.14 \\
C3 & 57.09 & 119.34 \\
C4 & 66.20 & 120.21 \\
C5 & 110.20 & 145.15 \\
\hline
\end{tabular}




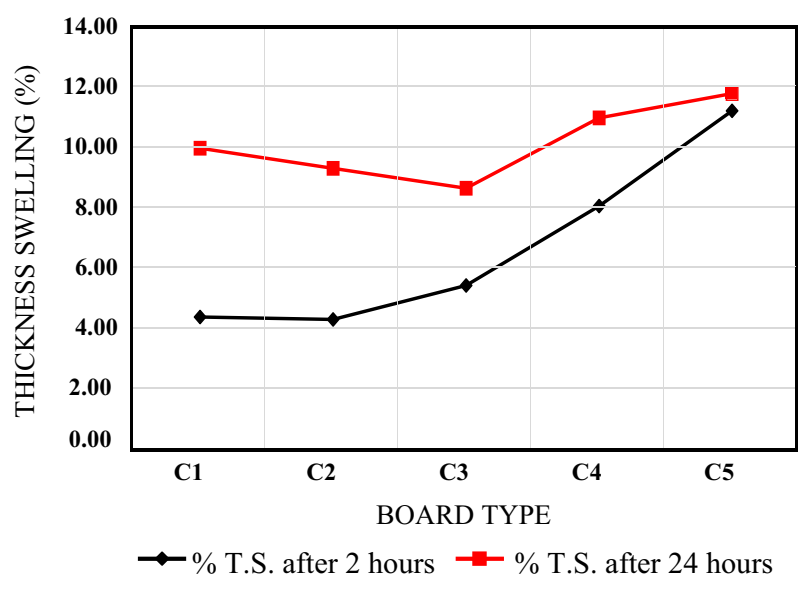

Fig. 2. Thickness swelling for different boards.

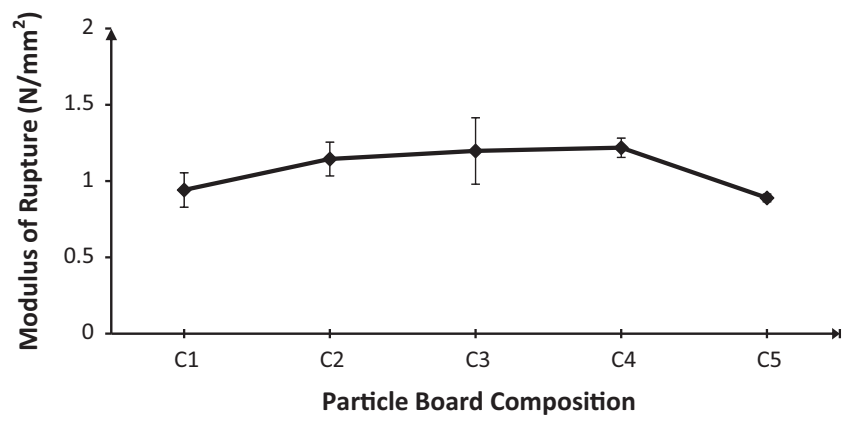

Fig. 3. Modulus of rupture of composite particle board.

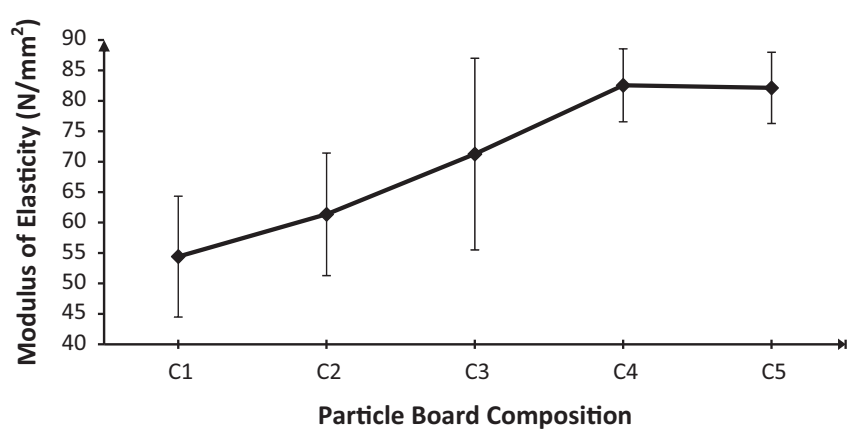

Fig. 4. Modulus of elasticity of composite particle board.

According to BS EN 13353 [29] panels of thickness greater than $20 \mathrm{~mm}$ but less than $30 \mathrm{~mm}$ were expected to have a minimum density of $420 \mathrm{~kg} / \mathrm{m}^{3}$. C1, C2, C3 and C4 possess densities greater than the minimum requirement, while $\mathrm{C5}$ with a density of $413 \mathrm{~kg} / \mathrm{m}^{3}$ did not meet up to the minimum requirement. However, panels intended for structural purposes that have densities greater than the minimum requirement were also required to have their minimum values for MOR and MOE to be $5 \mathrm{~N} / \mathrm{mm}^{2}$ and $400 \mathrm{~N} / \mathrm{mm}^{2}$ respectively. A similar result was obtained by Lawrence et al. [11]. From the result obtained from the tests which was shown in Figs. 3 and 4, none of the panels produced had values of MOE and MOR that met the minimum requirement. This therefore suggests that the panels cannot be used for structural or load bearing purposes. The low performances in MOE and MOR could be due to the relationship among the bond quantity, particle arrangement and low density of the agricultural residue CC used [28]. The particles used for the study may be smaller in size compared to those used by other researchers because they were produced from hammer mills [7]. Also, the compaction and curing method could also be responsible for the poor performances of the panels. Sekaluvu, et al. [11] investigated the properties of particleboards made from only CC and obtained mean values of MOE and MOR to range between $5.89 \pm 6.00 \mathrm{~N} / \mathrm{mm}^{2}$ to $61.82 \pm 10.09 \mathrm{~N} / \mathrm{mm}^{2}$ and $0.32 \pm 0.14 \mathrm{~N} / \mathrm{mm}^{2}$ to $1.50 \pm 0.16 \mathrm{~N} / \mathrm{mm}^{2}$ respectively which is similar to the results obtained in this research work. Therefore the particleboards produced for this research work can be used as ceiling boards and wall claddings.

\section{Conclusion}

It has been shown that it is possible to produce particleboards with less sophisticated machines and still obtain reasonable physical properties. From the results obtained, a 25-50\% replacement of SD with CC with particle size ranging from 1.18 to $3 \mathrm{~mm}$ and equal volume of adhesive exhibited favourable physical properties that are recommendable for indoor uses in buildings. However, the panels cannot be used for structural purposes or load bearing purposes because they exhibit poor mechanical properties which tend to improve as the composition of CC increased from $25 \%$ to $75 \%$. The MOR and MOE results obtained in this research work could lead to a conclusion that the mechanical properties of the panels were improved as the percentage of CC replacement increased. A $75 \%$ CC replacement had the highest value for both MOR and MOE but possess poor physical properties. Within the scope and limitations of this research, the panels with 50\% CC replacement are the most preferred for their physical and mechanical properties.

\section{References}

[1] José A. Rabi, Sérgio F. Santos, Gustavo H.D. Tonoli, Holmer Savastano Jr. Agricultural wastes as building materials: properties, performance and applications, in: Building Materials: Properties, Performance and Applications, Nova Science Publishers Inc., 2009. ISBN: 978-1-60741-082-9.

[2] C. Pandey, D. Sujatha, Crop Residues, the Alternate Raw Materials of Tomorrow for the Preparation of Composite Board, IPIRTI, Bangalore, 1999.

[3] V.K. Mathur, Composite materials from local resources, Constr. Build. Mater. 20 (2006) 470-477.

[4] Y.M.D. Adedeji, B. Ajayi, Cost-effective composite building panels for walls and ceilings in Nigeria, in: 11th Int. Inorganic-Bonded Fiber Composites Conference, 2008

[5] D. Wang, X.S. Sun, Low density particleboard from wheat straw and corn pith, Ind. Crops Prod. 15 (2002) 43-50.

[6] G. Nemli, H. Kirci, B. Sedar, N. Ay, Suitability of kiwi (Actinidia sinensis Planch.) prunings for particleboard manufacturing, Ind. Crops Prod. 17 (2003) 39-46.

[7] Ramadan Abdel-Sayed Nasser, Physical and mechanical properties of threelayer particleboard manufactured from the tree pruning of seven wood species, World Appl. Sci. J. 19 (5) (2012) 741-753.

[8] Iwona Frackowiak, Karolina mytKo, Ryszarda BeNdowsKa, Content of formaldehyde in lignocellulosic raw materials for particleboard production, Drewno. Pr. Nauk. Donies. Komunik. 55(188) (2012).

[9] T. Singh, Corn Waste Transformed Into Versatile Building Material, Retrieved January 30, 2015, from <http://inhabitat.com/corn-waste-transformed-intoversatile-building-material/>, 2010.

[10] C. Mgbemene, A. Rosenkranz, F. Pichelin, M. Lehmann, C. Job, H. Kimeng, S Mustapha, O. Nduka, Feasibility study on the Production of Particleboard from maize cobs, rice husks and groundnut shells using acacia mimosa tannin extract as the bonding adhesive, J. Archit. Eng. 20 (1) (2014) 04013006.

[11] Lawrence Sekaluvu, Peter Tumutegyereize, Nicholas Kiggundu, Investigation of factors affecting the production and properties of maize cob-particleboards, Waste Biomass Valorization 5 (1) (2014) 27-32.

[12] Joseph Khedari, Noppanun Nankongnab, Jongjit Hirunlabh, Sombat Teekasap New low-cost insulation particleboards from mixture of durian peel and coconut coir, Build. Environ. 39 (1) (2004) 59-65.

[13] Joseph Khedari, Sarocha Charoenvai, Jongjit Hirunlabh, New insulating particleboards from durian peel and coconut coir, Build. Environ. 38 (3) (2003) 435-441.

[14] Rafael Rodolfo de Melo, Diego Martins Stangerlin, Ricardo Robinson Campomanes Santana, Talita Dantas Pedrosa, Physical and mechanical properties of particleboard manufactured from wood, bamboo and rice husk, Mater. Res. 17 (3) (2014) 682-686. 
[15] Y.S. Oh, J.Y. Yoo, Properties of particleboard made from chili pepper stalks, J. Trop. For. Sci. 23 (4) (2011) 473-477.

[16] Mohd Iqbal Misnon, Shahril Anuar Bahari, Munirah Anuar, Jamil Salleh, Muhammad Ismail Ab Kadir, The mechanical and physical properties of agricultural waste particleboard reinforced with woven cotton fabrics, in: Universiti Teknologi MARA Kelantan Regional Academic Conference, 2009.

[17] Salim Hiziroglu, Rodney Holcomb, Some of the properties of three-layer particleboard made from eastern redcedar, Build. Environ. 40 (5) (2005) 719 723.

[18] Sylvester Ogah Obam, Properties of saw-dust, paper and starch composite ceiling board, Am. J. Sci. Ind. Res. (2012).

[19] J.A. Olorunmaiye, I.O. Ohijeagbon, Retrofitting composite ceiling boards with Jatropha curcas seedcake material, J. Prod. Eng. 18 (2015).

[20] N.A. Amenaghawon, W. Osayuki-Aguebor, C.O. Okieimen, Production of particle boards from corn cobs and cassava stalks: optimisation of mechanical properties using response surface methodology, J. Mater. Environ. Sci. 7 (4) (2016).

[21] Cengiz Guler, Ibrahim Bektas, Hulya Kalaycioglu, The experimental particleboard manufacture from sunflower stalks (Helianthus annuus L.) and Calabrian pine (Pinus brutia Ten.), For. Prod. J. 56 (4) (2006).

[22] Róger Moya, Diego Camacho, F. Roy Soto, Julio Mata-Segreda, Internal bond of particleboards made of three wood species mixture with empty fruit bunch of
Elaeis guineensis, leaves of Ananas comosus or Tetra Pak, Global Adv. Res. J. Agric. Sci. 4 (6) (2015) 241-247.

[23] BS EN 323, Wood-based Panels-Determination of Density, European Committee for Standardization (CEN), 1993.

[24] BS EN 310, Wood-base Panels - Determination of Modulus of Elasticity in Bending and of Bending Strength, European Committee for Standardization (CEN), 1993.

[25] Rose Marie Garay, Francisco MacDonald, María Luisa Acevedo, Beatriz Calderón, Jaime E. Araya, Particleboard Made With Crop Residues Mixed With Wood From Pinus Radiata, BioResources 4 (4) (2009) 1396-1408.

[26] U.D. Idris, V.S. Aigbodion, C.U. Atuanya, J. Abdullahi, Eco-friendly (water melon peels): alternatives to wood-based particleboard composites, Tribol. Ind. 33 (4) (2011).

[27] American National Standard Institute, ANSI A208.1, American National Standard -Particleboard, Composite Panel Association, 1999.

[28] M.V. Scatolino, D.W. Silva, R.F. Mendes, L.M. Mendes, Use of maize cob for production of particleboard, 2015 Retrieved from doi: 10.1590/S141370542013000400006.

[29] BS EN 13353, Solid Wood Panels (SWP) - Requirements, European Committee for Stabilization, 2003. 